\title{
Association Between Prostate Biopsy Results and Serum Vitamin D Levels
}

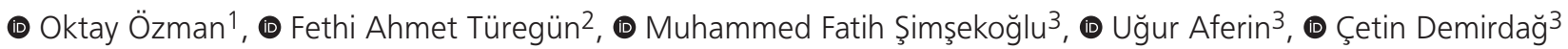 \\ 1 University of Health Sciences Turkey, Gaziosmanpaşa Training and Research Hospital, Istanbul, Turkey \\ 2 Güney Hospital, Clinic of Urology, Istanbul, Turkey \\ 3/stanbul University-Cerrahpaşa, Cerrahpaşa Faculty of Medicine, Department of Urology, Istanbul, Turkey
}

\begin{abstract}
Objective: This study investigates the relationship between pathological findings of prostate biopsy and serum $25(\mathrm{OH}) \mathrm{D}$ levels. Materials and Methods: Demographic, clinical and pathological data of 147 eligible patients were included in the study. All patients underwent transrectal ultrasound-guided prostate biopsy. Patients were divided into two groups; those with biopsy-proven prostate cancer (group 1$)$ and those with only benign pathological findings (group 2). Later, two subgroups were formed among the patients diagnosed with prostate cancer (group 1); patients with serum 25 (OH) D levels above and below $20 \mathrm{ng} / \mathrm{mL}$. All groups and subgroups were compared regarding clinical and pathological parameters. Finally, patients were divided according to International Society of Urological Pathology (ISUP) grade groups.

Results: Serum $25(\mathrm{OH})$ D level of patients with prostate cancer (group 1: 15.6 $\pm 7.0 \mathrm{ng} / \mathrm{mL}$ ) was slightly lower than the non-cancer group (group 2: $16.0 \pm 9.2$ $\mathrm{ng} / \mathrm{mL}$ ) ( $p=0.38$ ). On analysis of variance, there was a statistically significant difference between ISUP grade 1 , grade $2-3$ and grade $4-5$ ( $p=0.012$ ). Patients with clinically insignificant prostate cancer (ISUP grade 1) had significantly higher serum $25(\mathrm{OH}) \mathrm{D}$ levels than other prostate cancer patients ( $p=0.023)$. There was a weak negative correlation between serum $25(\mathrm{OH})$ D levels and ISUP grades $(r=-0.319, p=0.01)$.

Conclusion: There was no association between the diagnosis of prostate cancer and vitamin D deficiency. However, promising results have been obtained in favour of prostate cancer aggressiveness in vitamin D deficiency.
\end{abstract}

Keywords: Prostate cancer, vitamin D, biopsy

\section{Introduction}

Prostate cancer is the second most common cancer in men worldwide, according to current data of the GLOBOCAN study (1). Many endogenous and exogenous factors' effects on the pathogenesis of prostate cancer have been investigated. Since the hypothesis explaining cancer's development with daylightvitamin D has been proposed by Garland and Garland (2) 40 years ago, many biochemical, genetic, epidemiological and clinical studies have been conducted on the relationship between vitamin $D$ and prostate cancer. A secondary analysis of the VITAL study suggests that vitamin D supplementation may reduce prostate cancer incidence (3).

Despite the promising results from the VITAL study at the end of 40 years, vitamin D deficiency's role in prostate cancer pathophysiology has not been fully elucidated. It is emphasised that mitochondrial activation of vitamin $D$ in prostate cells is also a process that affects mitochondrial metabolism (4). Vitamin D deficiency develops a metabolic tendency in favour of oxidation in mitochondrial functions. There are also biochemical studies that try to explain the prostate cancer's pathophysiology through vitamin D's regulatory effect on androgen intracrinology (5).

A meta-analysis investigating vitamin D deficiency cases in Turkey was published recently (6). The prevalence of vitamin D deficiency was high (58.9\% to $66.6 \%$ ). It was emphasised that community-based follow-up and supplementation were necessary. Studies investigating the relationship between pathological findings and vitamin $D$ deficiency in patients with prostate cancer in our country are insufficient. This study investigates the relationship between pathological findings of prostate biopsy and serum 25-hydroxyvitamin D [25 (OH) D] levels.

\section{Materials and Methods}

After ethical approval (İstanbul University-Cerrahpaşa, Cerrahpaşa Faculty of Medicine, number: 83045809/604.01/02-107680),

Cite this article as: Özman O, Türegün FA, Şimşekoğlu MF, Aferin U, Demirdağ Ç. Association Between Prostate Biopsy Results and Serum Vitamin D Levels. Bull Urooncol 2021;20(2):83-86

Address for Correspondence: Oktay Özman, University of Health Sciences Turkey, Gaziosmanpaşa Training and Research Hospital, İstanbul, Turkey Phone: +90 2129453000 E-mail: ozmanoktay@hotmail.com ORCID-ID: orcid.org/0000-0003-2499-8947 Received: 22.03.2020 Accepted: 02.07.2020 
the data of 151 patients who underwent prostate biopsy due to increased serum prostate-specific antigen (PSA) levels and/ or positive rectal examination findings were prospectively evaluated and collected. Patients with the following exclusion criteria were excluded from the study:

1. Patients receiving vitamin $D$ and calcium supplementation

2. Patients with known liver or kidney dysfunction

3. Biopsies diagnosed with ASAP and/or HGPIN but without prostate cancer

\section{Patients with other malignancy}

Demographic, clinical and pathological data of 147 eligible patients were included in the study. All patients underwent transrectal ultrasound-guided prostate biopsy. All biopsies were performed as previously described in the literature (7). Six cores were obtained from patients with a high probability of prostate cancer by the clinical diagnosis (e.g. PSA $>100 \mathrm{ng} / \mathrm{dL}$ or imaging findings favouring prostate cancer). Twenty-eight core biopsy specimens were obtained from patients who underwent repeat biopsy and 16 cores from patients with transrectal prostate volumes of $60 \mathrm{~mL}$ or more. Standard 12 cores were taken from all other patients. All samples were evaluated by the same uropathologist.

According to the published evidence, $25(\mathrm{OH}) \mathrm{D}$ is considered the best marker for body vitamin $\mathrm{D}$ status (8). After patient consent was obtained, serum $25(\mathrm{OH})$ D levels of all patients were measured in the same laboratory, with venous blood samples taken before the biopsy. All blood samples were taken in the summer or spring for serum vitamin D measurements. Serum samples were sent to the biochemistry laboratory as soon as they were received. Samples were stored at room temperature before measurement. Serum 25 (OD) D was measured by the liquid chromatography-tandem mass spectrometry method (9). The $20 \mathrm{ng} / \mathrm{mL}$ level defined by the World Health Organisation and recommended by the Institute of Medicine was considered the cut-off value for "vitamin D deficiency" $(10,11)$.

Patients were divided into two groups according to the presence of prostate cancer on biopsy; those with prostate cancer (group 1) and those with only benign pathological findings, such as chronic prostatitis and benign prostatic hyperplasia (group 2). Groups were compared for age, body mass index (BMI), serum

\begin{tabular}{|l|l|l|l|}
\hline \multicolumn{4}{|l|}{ Table 1. Demographic and clinical characteristics of groups } \\
\hline Variables (means) & $\begin{array}{l}\text { PCa cases } \\
(\mathbf{n = 6 2}) \\
\text { Group 1 }\end{array}$ & $\begin{array}{l}\text { Negative } \\
\text { biopsies (n=85) } \\
\text { Group 2 }\end{array}$ & p-value \\
\hline $\begin{array}{l}\text { Age, years (median, } \\
\text { range) }\end{array}$ & $\begin{array}{l}65.6 \pm 7.8 \\
(66,43-81)\end{array}$ & $\begin{array}{l}61.9 \pm 7.9 \\
(63,41-83)\end{array}$ & 0.007 \\
\hline BMl, kg/m² & $26.1 \pm 4.2$ & $26.6 \pm 3.6$ & 0.48 \\
\hline Serum PSA, ng/dL & $27.8 \pm 61$ & $8.5 \pm 6.9$ & 0.01 \\
\hline PSA density & $0.68 \pm 1.71$ & $0.19 \pm 0.2$ & 0.01 \\
\hline $\begin{array}{l}\text { Serum 25 (OH) D3, } \\
\text { ng/mL }\end{array}$ & $15.6 \pm 7.0$ & $16.0 \pm 9.2$ & 0.38 \\
\hline Prostate volume, mL & $45.7 \pm 25.6$ & $53.9 \pm 26.2$ & 0.03 \\
\hline BMl: Body mass index, PSA: Prostate-specific antigen, PCa: Prostate cancer \\
\hline
\end{tabular}

PSA, $25(\mathrm{OH})$ D levels and prostate volumes (Table 1). Later, two subgroups were formed among the patients diagnosed with prostate cancer (group 1); patients with serum $25(\mathrm{OH})$ D levels above and below $20 \mathrm{ng} / \mathrm{mL}$. The subgroups were compared regarding PSA, digital rectal examination findings, prostate volume and pathological findings (Table 2). Finally, patients with prostate cancer were classified according to International Society of Urological Pathology (ISUP) grade groups. Serum 25 (OH) D levels of ISUP grade 1, grade 2-3 and 4-5 patients were compared. In addition, grade 1 , which is considered clinically insignificant, was compared with the other groups (Table 3).

\section{Statistical Analysis}

First, the samples' normal distribution for all variables was checked by the Kolmogorov-Smirnov test. All samples showed a normal distribution. The Student's t-test and ANOVA (for more than two groups) were used to investigate the difference between the continuous variables. Chi-square with Yate's correction test was used for the difference between categorical variables. Correlation analyses were done with Spearman's test. All statistical analyses were performed using the Statistical Package for the Social Sciences v. 22 (SPSS Inc, Illinois, USA). A $\mathrm{p}<0.05$ was considered statistically significant.

\begin{tabular}{|c|c|c|c|}
\hline Characteristic & $\begin{array}{l}<20 \mathrm{ng} / \mathrm{mL} 25 \\
(\mathrm{OH}) \mathrm{D3} \\
(\mathrm{n}=35)\end{array}$ & $\begin{array}{l}>20 \mathrm{ng} / \mathrm{mL} \\
25(\mathrm{OH}) \mathrm{D3} \\
(\mathrm{n}=27)\end{array}$ & p-value \\
\hline Age & $66.7 \pm 7.3$ & $64.2 \pm 8.3$ & 0.22 \\
\hline $\begin{array}{l}\text { Total Gleason score } \\
\text { (median) }\end{array}$ & 7 & 6 & 0.09 \\
\hline Gleason pattern $\geq 4$ Rate & $54 \%(19 / 35)$ & $44 \%(12 / 27)$ & 0.61 \\
\hline $\mathrm{PSA}, \mathrm{Ng} / \mathrm{mL}$ & $27.1 \pm 64.5$ & $24.1 \pm 57.4$ & 0.85 \\
\hline PSA density & $0.8 \pm 2.1$ & $0.52 \pm 0.92$ & 0.52 \\
\hline \multicolumn{4}{|l|}{ D'Amico risk classification } \\
\hline Low & $25.7 \%(9 / 35)$ & $29.6 \%(8 / 27)$ & \\
\hline Intermediate & $28.6 \%(10 / 35)$ & $40.8 \%(11 / 27)$ & 0.41 \\
\hline High & $45.7 \%(16 / 35)$ & $29.6 \%(8 / 27)$ & \\
\hline DRE Finding & $46 \%(16 / 35)$ & $26 \%(7 / 27)$ & 0.11 \\
\hline Prostate volume $(\mathrm{mL})$ & $42.3 \pm 15.8$ & $50.1 \pm 34.4$ & 0.24 \\
\hline Mean of positive core rate & $43.1 \pm 32.5$ & $27.8 \pm 26.9$ & 0.05 \\
\hline
\end{tabular}

Table 3. Comparison of serum $25(\mathrm{OH})$ D levels according to ISUP grade groups

\begin{tabular}{|l|l|l|l|l|}
\hline Characteristic & ISUP 1 & ISUP 2-3 & ISUP 4-5 & p-value \\
\hline Number (n,\%) & $\begin{array}{l}30 / 62 \\
(48.4 \%)\end{array}$ & $\begin{array}{l}23 / 62 \\
(37.1 \%)\end{array}$ & $\begin{array}{l}9 / 62 \\
(14.5 \%)\end{array}$ & \\
\hline Serum 25 (OH) D, ng/mL & $17.8 \pm 7.4$ & $14.8 \pm 6.4$ & $10.3 \pm 4.1$ & 0.012 \\
\hline p-value (ISUP 1 vs others) & & 0.023 & & \\
\hline
\end{tabular}

ISUP: International society of urological pathology, ISUP: International society of urological pathology 


\section{Results}

Forty-two per cent $(62 / 147)$ of the patients had prostate cancer. Serum $25(\mathrm{OH})$ D levels were lower than $20 \mathrm{ng} / \mathrm{mL}$ in $84(57.1 \%)$ of 147 patients. There was no difference between serum $25(\mathrm{OH}) \mathrm{D}$ levels of patients with prostate cancer (group 1: $15.6 \pm 7.0 \mathrm{ng} / \mathrm{mL}$ ) and the non-cancer group (group 2: 16.0 \pm 9.2 $\mathrm{ng} / \mathrm{mL})(\mathrm{p}=0.38)$. The prostate cancer detection rate of patients with serum $25(\mathrm{OH})$ D less than $20 \mathrm{ng} / \mathrm{mL}(35 / 84,41.7 \%)$ was similar to others $(27 / 63,42.9 \%)(p=0.98)$.

There were statistically significant differences between groups 1 and 2 regarding mean age, serum PSA level, PSA density and prostate volume $(p=0.007, p=0.01, p=0.01$ and $p=0.03$, respectively). The mean age of the patients in group 1 (65.6 \pm 7.8 years) was higher than group 2 (61.9 \pm 7.9 years). The patients' serum PSA levels in group $1(27.8 \pm 61 \mathrm{ng} / \mathrm{dL})$ were significantly higher than group $2(8.5 \pm 6.9 \mathrm{ng} / \mathrm{dL})$. Despite this finding, the mean prostate volumes $(53.9 \pm 26.2 \mathrm{~mL})$ of group 2 were higher than group $1(45.7 \pm 25.6 \mathrm{~mL})$. There was no statistically significant difference between the groups regarding BMI (group 1: $26.1 \pm 4.2$, group 2: $26.6 \pm 3.6, p=0.48$ ) (Table 1).

In addition, we investigated the relationship between clinical and pathological aggressiveness of prostate cancer and vitamin D deficiency in a subgroup analysis (Table 2). The median Gleason score of patients with a prostate cancer diagnosis had a serum 25 $(\mathrm{OH}) \mathrm{D}$ level of less than $20 \mathrm{ng} / \mathrm{mL}$ (Gleason 7) was higher than that of patients with a serum $25(\mathrm{OH})$ D level of more than 20 $\mathrm{ng} / \mathrm{mL}$ (Gleason 6). However, this difference was not statistically significant $(p=0.09)$. Similarly, the proportion of patients with Gleason pattern 4 and above was slightly higher in patients with low serum $25(\mathrm{OH}) \mathrm{D}$ [54\% (19/35) vs 44\% (12/27), $\mathrm{p}=0.61]$. Patients with low serum $25(\mathrm{OH}) \mathrm{D}$ had higher serum PSA levels, positive core rates, positive digital rectal examination findings, and lower mean prostate volumes (Table 2). However, none of these differences were statistically significant $(p=0.85, p=0.11$, $\mathrm{p}=0.05$ and $\mathrm{p}=0.24$, respectively).

Serum $25(\mathrm{OH})$ D levels of patients with ISUP grade 1 were higher than grade $2-3$ patients $(17.8 \pm 7.4 \mathrm{ng} / \mathrm{mL}$ and $14.8 \pm 6.4 \mathrm{ng} / \mathrm{mL}$, respectively). Serum $25(\mathrm{OH}) \mathrm{D}$ levels were lowest in patients with ISUP grade 4-5 prostate cancer $(10.3 \pm 4.1 \mathrm{ng} / \mathrm{mL})$. There was a statistically significant difference between ISUP grade 1, grade 2-3, and grade 4-5 ( $p=0.012)$ on analysis of variance. Patients with clinically insignificant prostate cancer (ISUP grade 1) had significantly higher serum $25(\mathrm{OH}) \mathrm{D}$ levels than other prostate cancer patients $(p=0.023)$. (Table 3$)$. There was a weak negative correlation between serum $25(\mathrm{OH}) \mathrm{D}$ levels and ISUP grades $(r=-0.319, p=0.01)$.

\section{Discussion}

Our study's primary outcomes were relationships between prostate cancer biopsy parameters and serum vitamin D status. Although the findings indicated more undifferentiated prostate cancer in vitamin D deficiency, no statistically significant results were obtained from analyses where vitamin $\mathrm{D}$ was considered a categorical variable. However, when we considered serum 25 $(\mathrm{OH}) \mathrm{D}$ levels as a continuous variable, we found that vitamin D levels decreased as the ISUP grade increased $(p=0.012)$. Vitamin
D levels of patients with clinically insignificant prostate cancer (ISUP grade 1) were significantly higher than patients with ISUP grade 2 and above prostate cancer $(p=0.023)$.

Published studies show a significant relationship between prediagnostic vitamin D levels and prostate cancer mortality $(12,13)$. Other investigations suggest that high vitamin D levels can improve prostate cancer survival. Nyame et al. (14) showed that serum vitamin D levels were significantly lower in patients with a cancer pathology of Gleason 4 and above after radical prostatectomy.

On the other hand, studies report negative results about the vitamin D-prostate cancer relationship. Stephan et al. (15) found no association between prostate cancer aggressiveness and vitamin D status. Also, $25(\mathrm{OH}) \mathrm{D}$ was not different between men with prostate cancer vs no evidence of malignancy. In another study, researchers found increased odds of a prostate cancer diagnosis on prostate biopsy in patients with serum 25 $(\mathrm{OH}) \mathrm{D}<20 \mathrm{ng} / \mathrm{mL}$ (16). The results of this study were obtained from the data of African American patients. African American men are a risky group for vitamin D deficiency and aggressive prostate cancer (17). However, studies have shown that these men develop prostate tissue responses against vitamin D deficiency (18).

There are many measurable forms of vitamin $D$ in the serum. In our study, the $25(\mathrm{OH}) \mathrm{D}$ form, shown to reflect the body's vitamin D status best, was used (8). However, we may need to change our perspective on the relationship between prostate cancer and vitamin D. The $1.25(\mathrm{OH}) 2 \mathrm{D} / 25(\mathrm{OH}) \mathrm{D}$ molar ratio has been shown to reflect prostate cancer aggressiveness better in a recent study (19). Murphy et al. (16) used $12 \mathrm{ng} / \mathrm{mL}$ as the cut-off value for $25(\mathrm{OH})$ D deficiency. According to this study's results, there was a relationship between Gleason 8 and above prostate cancer and vitamin D deficiency.

The overall rate in the male population is approximately $90 \%$, according to the population-based TURDEP-II study, which investigated vitamin $\mathrm{D}$ deficiency in our country [the deficiency was defined as $25(\mathrm{OH})$ D concentration $\leq 20 \mathrm{ng} / \mathrm{mL}$ ] (20). According to age groups, the highest prevalence (91.9\%) was over 65 years in the subgroup analysis. Prostate cancer risk increases significantly in this age group. Vitamin D deficiency was found in $57 \%$ of our cohort. This difference was because our cohort was a selected group of patients that did not fully reflect the population.

The relationship between vitamin $D$ and the prostate may not be limited to malignant processes. A study conducted in 2017 showed that prostate volume was inversely correlated with vitamin D (as a continuous and categorical variable) (21). A significant relationship was found between serum $25(\mathrm{OH})$ D less than $30 \mathrm{ng} / \mathrm{ml}$ and the risk of prostate volume above 40 grammes in this study. Similar results have been reported in a study conducted in China (22). Our study showed that the prostate volumes of the vitamin D deficient group were higher than. However, the difference was not statistically significant $(p=0.24)$.

In summary, the most remarkable result of our study is that the patients who have clinically insignificant prostate cancer have significantly higher vitamin D levels. With studies conducted 
with more extensive series and this theoretical framework, vitamin D cut-off value as an active surveillance criterion can be determined. The effect of vitamin $D$ supplementation on active surveillance results can be investigated.

\section{Study Limitations}

There were many internal and external limitations in our study. First, we are aware that we look at the relationship between vitamin $\mathrm{D}$ and prostate cancer indirectly. Clinically proven prostate cancer is the result of a long process of carcinogenesis. Also, patients' final prostatectomy pathology results could not be included in the study. Serum vitamin D levels at the time of diagnosis cannot be considered as a direct indicator of vitamin D status in an entire process. Controversial issues that are mainly related to vitamin $D$ caused some external limitations. Uncertainties regarding the body's vitamin D status remain, including its optimal molecular form, best cut-off value, deficiency or inadequacy (23). On the other hand, discussions suggesting a protective role of vitamin $\mathrm{D}$ levels in prostate cancer should be investigated independently.

\section{Conclusion}

There was no correlation between prostate cancer diagnosis and vitamin $\mathrm{D}$ deficiency. However, promising results have been obtained in favour of prostate cancer aggressiveness in vitamin D deficiency. Serum $25(\mathrm{OH})$ D levels were significantly lower in patients with high ISUP grade prostate cancer on prostate biopsy. Patients with clinically insignificant prostate cancer have lower $25(\mathrm{OH}) \mathrm{D}$ levels.

\section{Acknowledgements}

Publication: The results of the study were not published in full or in part in form of abstracts.

Contribution: There is not any contributors who may not be listed as authors.

Conflict of Interest: No conflict of interest was declared by the authors.

Financial Disclosure: The authors declared that this study received no financial support.

\section{Ethics}

Ethics Committee Approval: Ethical approval (İstanbul University-Cerrahpaşa, Cerrahpaşa Faculty of Medicine, number: 83045809/604.01/02-107680).

Informed Consent: Patient consent was obtained.

Peer-review: Externally peer-reviewed.

\section{Authorship Contributions}

Concept: F.A.T., U.A., Ç.D., Design: F.A.T., U.A., Ç.D., Data Collection or Processing: O.Ö., F.A.T., Analysis or Interpretation: O.Ö., Literature Search: O.Ö., M.F.Ş., U.A., Writing: F.A.T.

\section{References}

1. Bray F, Ferlay J, Soerjomataram I, et al. Global cancer statistics 2018 : GLOBOCAN estimates of incidence and mortality worldwide for 36 cancers in 185 countries. CA Cancer J Clin 2018;68:394-424.
2. Garland C, Garland FC. Do sunlight and vitamin D reduce the likelihood of colon cancer? Int J Epidemiol 1980;9:227-231.

3. Grant WB. Review of recent advances in understanding the role of vitamin $\mathrm{D}$ in reducing cancer risk: breast, colorectal, prostate, and overall cancer. Anticancer Res 2020;40:491-499.

4. Blajszczak CC, Nonn L. Vitamin D regulates prostate cell metabolism via genomic and non-genomic mitochondrial redox-dependent mechanisms. J Steroid Biochem Mol Biol 2019;195:105484. doi: 10.1016/j.jsbmb.2019.105484.

5. Smith KW, Thompson PD, Rodriguez EP, et al. Effects of vitamin $\mathrm{D}$ as a regulator of androgen intracrinology in LNCAP prostate cancer cells. Biochem Biophys Res Commun 2019;519:579-584.

6. Alpdemir M, Alpdemir MF. Vitamin D deficiency status in Turkey: a meta-analysis. Int J Med Biochem 2019;2:118-131.

7. Obek C, Ozkan B, Tunc B, et al. Comparison of 3 different methods of anesthesia before transrectal prostate biopsy: a prospective randomized trial. J Urol 2004;172:502-505.

8. Bouillon R, Carmeliet G. Vitamin D insufficiency: definition, diagnosis and management. Best Pract Res Clin Endocrinol Metab 2018;32:669-684.

9. Shin SY, Kwon M], Song J, et al. Measurement of serum total vitamin $\mathrm{D}(25-\mathrm{OH})$ using automated Immunoassay in comparison [corrected] with liquid chromatography tandem-mass spectrometry. J Clin Lab Anal 2013;27:284-289.

10. World Health Organization Scientific Group on the Prevention and Management of Osteoporosis 2003. Prevention and management of osteoporosis: report of a WHO scientific group. Geneva: World Health Organization.

11. Atkinson SA. [The new dietary reference intakes from the Institute of Medicine for calcium and vitamin D]. Perspect Infirm 2011;8:5. [Article in French]

12. Fang F, Kasperzyk JL, Shui I, et al. Prediagnostic plasma vitamin D metabolites and mortality among patients with prostate cancer. PLoS One 2011;6:e18625. doi: 10.1371/journal.pone.0018625.

13. Brändstedt J, Almquist $M$, Manjer J, Malm J. Vitamin D, PTH, and calcium in relation to survival following prostate cancer. Cancer Causes Control 2016;27:669-677.

14. Nyame YA, Murphy AB, Bowen DK, et al. Associations between serum vitamin $D$ and adverse pathology in men undergoing radical prostatectomy. J Clin Oncol 2016;34:1345-1349.

15. Stephan C, Lein M, Matalon J, et al. Serum vitamin D is not helpful for predicting prostate cancer aggressiveness compared with the prostate health index. J Urol 2016;196:709-714.

16. Murphy AB, Nyame $Y$, Martin IK, et al. Vitamin D deficiency predicts prostate biopsy outcomes. Clin Cancer Res 2014;20:2289-2299.

17. Ginde AA, Liu MC, Cmarago Jr CA. Demographic differences and trends of vitamin D insufficiency in the US population, 1988-2004. Arch Intern Med 2009;169:626-632.

18. Richards Z, Batai K, Farhat R, et al. Prostatic compensation of the vitamin D axis in African American men. JCI Insight 2017;2:e91054. doi: 10.1172/jci.insight.91054.

19. Ramakrishnan S, Steck SE, Arab L, et al. Association among plasma $1,25(\mathrm{OH}) 2 \mathrm{D}$, ratio of $1,25(\mathrm{OH}) 2 \mathrm{D}$ to $25(\mathrm{OH}) \mathrm{D}$, and prostate cancer aggressiveness. Prostate 2019;79:1117-1124.

20. Satman I, Ozbey N, Boztepe $\mathrm{H}$, et al. Prevalence and correlates of vitamin $D$ deficiency in Turkish adults. Endocrine Abstracts 2013;32:135.

21. Murphy AB, Nyame YA, Batai K, et al. Does prostate volume correlate with vitamin $\mathrm{D}$ deficiency among men undergoing prostate biopsy? Prostate Cancer Prostatic Dis 2017; 20:55-60.

22. Zhang W, Zheng X, Wang Y, Xiao H. Vitamin D deficiency as a potential marker of benign prostatic hyperplasia. Urology 2016;97:212-218.

23. Manson JE, Brannon PM, Rosen CJ, Taylor CL. Vitamin D deficiency Is there really a pandemic? N Engl J Med 2016;375:1817-1820. 